\title{
1. Conceptual and theoretical frame
}

One must learn by doing the thing; for though you think you know it, you have no certainty until you try. Sophocles, Greek playwright, fourth century BC

Imagine a business educator in an institution of higher education, teaching a course in accounting, finance, informatics, economics, marketing, management, or the like. In the classroom, silent concentration on a brief reading gives way to a buzz of excitement and a rise in background noise as the students engage in a conversation, each party acting out their assigned part in a scenario that they might encounter in business organizations. The educator wanders about the classroom, listening in on a conversation here, answering a question there, and interjecting a useful suggestion every so often.

In this volume, we describe role-playing simulations as an active learning methodology for capturing students' attention and generating greater interest in a dynamic classroom experience. The situation depicted above may sound very appealing, yet interest in this volume may come about for a number of different reasons. Some readers may never have used role-playing as a technique in the classroom, but are intrigued by its potential for engaging students and enlivening the learning environment. For other readers, the level of student engagement that we just described may not require much imagination, but there may be less familiarity with the theories of teaching and learning that underlie role-playing as a pedagogical technique. Still other readers may be seeking more information in attempting to persuade skeptical students, colleagues, and/or administrators about the value of role-playing in the classroom. And there may be other readers who have tried role-plays in their classroom and were discouraged by their students' lack of engagement.

If you fall into any of the categories above, this volume is written for you. Role-play simulations, or "role-plays" as we refer to them throughout this volume, involve immersing students in a scenario in which they are assigned to roles and asked to act out their role as though they were actually the individual in that situation (McKeachie and Svinicki, 2013). The concept of role-playing draws from a dramaturgical metaphor whereby students imagine how individuals in a specified situation would 
be likely to act and then reenact those behaviors accordingly (Nicolaidis and Liotas, 2006). Role-playing, at its best, resonates for many students and faculty because of its connection to the play time of early childhood, especially a world of "make-believe" in which ideas and behaviors are tried out in a relatively safe space. As Cook (1917) described it:

A natural education is by practice, by doing things, and not by instruction ... [I]t is well to let [a student] try as much as he can for himself under guidance. It would not be wise to send a child innocent into the big world; and talking is of poor avail. But it is possible to hold rehearsals, to try our strength in a make-believe big world. And that is Play. (pp. 145-146)

The purpose of this book is to explain the foundations of role-playing as an active, experiential, interactive teaching method for business educators, and to provide guidance for educators in the development and implementation of role-plays in the classroom. In this opening chapter, we begin with a brief overview of active learning practices and concepts, with particular attention to role-playing. We explain what role-playing is and what it is not, distinguishing it from other methods of active, experiential learning methodologies. We trace the historical and theoretical underpinnings of role-playing, going back to the dramaturgy of ancient Greek theatre through the Enlightenment and to the roots of active, experiential learning more generally, and role-playing specifically, in twentieth-century U.S. education. We then discuss the key theoretical frameworks that explain the philosophical underpinnings of the role-play methodology. We offer educators insight into eight benefits of role-plays in the business classroom and three types of learning outcome (cognitive, behavioral, and affective) associated with each type of benefit. We conclude by highlighting potential liabilities that educators should be aware of in choosing whether to use role-plays in the classroom.

In Chapter 2, we discuss a variety of considerations for educators interested in using role-plays. We offer specific ideas and suggestions for using role-plays with different class sizes, with students at different academic levels and with different levels of work experience and maturity, in classes that meet in person or virtually, with respect to course structure and the timing of role-plays within class periods and within the framework of one's institutional climate and assessment demands. We also discuss how to prepare and execute the debrief component of role-plays, and describe essential factors that educators should address in choosing to use or design their own role-play simulation. In Chapter 3, we provide 
a step-by-step overview of how to prepare and implement role-plays with specific, class-tested examples and materials to make them immediately useful to the educator. We conclude with an annotated bibliography of resources for further reading.

Active learning methodologies for enhancing student engagement are an increasingly important point of emphasis for business educators, driven by greater competition for students and, in turn, an increased emphasis on student retention (Cohen and Kisker, 2010). Role-playing and similarly student-centered, engaging methods of active learning are perceived as important strategies for facilitating student retention (Tuckman and Kennedy, 2011). Additionally, major international accrediting agencies such as the European Quality Improvement System (EQUIS) and the Association to Advance Collegiate Schools of Business (AACSB) have promoted active learning methods as a basis of skills development. These standards are built on accumulating evidence that active learning methods not only facilitate student engagement and retention (Cox et al., 2005) but also student achievement (Burch et al., 2015; Prince, 2004). Thus, role-playing can be a valuable approach for capturing student interest and leveraging that interest to facilitate better learning outcomes (Clawson, 2006).

\section{ACTIVE LEARNING - A BRIEF REVIEW}

Active learning involves instructional practices and tactics that engage students as participants in the learning process (Prince, 2004). As we describe later in this chapter, the learning process is an iterative, ongoing sequence of activities intended to increase student awareness and understanding (Ferguson et al., 2016). Active learning facilitates a learning process that involves growth based on exposure to and concrete experiences with concepts and ideas, alternating with reflections on those experiences (Kolb and Kolb, 2005). Active learning is thus contrasted with traditional, more passive forms of instruction, particularly traditional lecture (e.g., "chalk and talk," Becker and Watts, 1996).

Active learning can include a variety of methods and techniques that range from supplementing to supplanting lectures. For instance, a simple active learning approach involves pausing periodically during the lecture to allow students to compare their notes with others and consolidate what they have learned so far (Prince, 2004). This so-called "pause procedure" has been shown to be quite effective in improving student retention and recall of concepts (Ruhl et al., 1987). Slightly more involved than the 
pause procedure is "think-pair-share," where, in small groups, students quickly and informally discuss a question that has been posed by the educator before discussing it with the class as a whole (McKeachie and Svinicki, 2013).

At the other end of the active learning spectrum, teaching methods can largely supplant lectures as the primary activities of in-class time. For instance, the class period can be built around students' engagement in an activity, such as collaborative categorizations of concepts via "mind mapping," a process of writing down and capturing relationships among thoughts, beliefs, and ideas in a group (Nesbit and Adesope, 2006). Taking active learning even further, some educators utilize an inverted or "flipped" classroom in which lectures are recorded for students to watch at home, and then in-class time is devoted to working out problems or discussing and debating material from the lecture (O'Flaherty and Phillips, 2015). In practice, however, many educators incorporate active learning in conjunction with lectures by interspersing activities and exercises to illustrate key concepts from the lecture, break up the class time, and increase student engagement (Kenworthy-U'Ren and Erickson, 2009).

Why have active learning approaches garnered growing attention in higher education generally and business education more specifically? Active learning supports two outcomes that have increased dramatically in relevance to educators in the past four decades: student engagement and student learning outcomes.

\section{Student Engagement}

Since the 1980s, there has been growing interest in how to improve student success in terms of outcomes such as retention, degree completion, and subsequent employment, and student engagement has been a cornerstone of efforts to facilitate student success (Zepke and Leach, 2010). The growing interest in student engagement in the United States, for instance, coincided with dire predictions of dramatically declining university enrollment in the years after the "Baby Boomer" generation that followed the Second World War completed their education (Cohen and Kisker, 2010). Contemporary researchers have expressed renewed concerns about depressed enrollment levels from unfavorable demographic trends (Grawe, 2018). More broadly, student engagement is widely viewed as an important outcome to universities in meeting their mission of educating students for jobs in a modern, globalized economy (Masika and Jones, 2016; Zhoc et al., 2019). Indeed, active learning 
strategies that foster student engagement are viewed as an antidote to the dreary picture of lecture-heavy, educator-centric, uninspiring teaching approaches (Becker and Watts, 1996; Zepke and Leach, 2010).

Researchers have suggested a variety of structural reforms for colleges and universities to promote student involvement and academic and social integration, including the growth of student affairs infrastructure and support services (Tinto, 1987). Moving beyond structural institutional changes, researchers have extended Tinto's conclusions to argue for changes to student interactions with faculty, both in and out of the classroom (Kuh et al., 2006). They have found that more interactive delivery of course material is associated with students' social integration (i.e., finding friends and feeling included in campus life), institutional commitment, and retention (Braxton et al., 2000). Indeed, faculty that integrate active learning methods such as role-play into their courses are increasingly seen as an important element of institutional recruitment and retention strategies, as student involvement has been found to be an important contributor to student retention and performance (McCallum et al., 2015). In all, there is substantial evidence that active learning strategies, such as the use of role-plays, promote greater student engagement and facilitate student involvement, commitment, and retention (Masika and Jones, 2016; Prince, 2004).

\section{Student Learning Outcomes}

In addition to positive outcomes in terms of student engagement, active learning methods should also facilitate intended student learning outcomes. Student learning outcomes may include: comprehension and retention of knowledge; skills acquisition; the development of study habits; a desire for lifelong learning; affective outcomes such as changes in attitudes and beliefs; and the ability to analyze, synthesize, and engage in other higher-level thought processes (Bloom, 1956; King et al., 2007; Shephard, 2008). Indeed, an overarching goal of active learning is to promote such student learning outcomes (e.g., Felder et al., 2000). Active learning methods are believed to surpass traditional lectures with respect to students' retention of material and development of critical thinking skills (McKeachie and Svinicki, 2013).

Many advocates of active learning argue that the effectiveness of tactics such as role-plays for improving student learning outcomes has to do with managing student attention span and communicating key concepts in multiple ways that make them more salient and appeal to differ- 
ent learning styles (Prince, 2004). For instance, Wankat (2002) suggests that the average student attention span during a lecture is approximately 15 minutes, at which point student retention of material drops off dramatically. In another study, researchers found that students remember 70 percent of the information from the first ten minutes of a lecture, but only about 20 percent of the information delivered in the last ten minutes of a lecture (Hartley and Davies, 1978; see also Wilson and Korn, 2007, for a more recent discussion of student attention spans). Alternating active learning techniques and exercises such as role-plays with lectures, then, not only breaks up monotony but also has the potential to reset student attention and promote engagement through more of the class period (Prince, 2004).

Educators have both an opportunity and an obligation to promote a learning environment that reaches students at their current level of understanding and scholarship, and holds the potential for delivering better learning outcomes by incorporating active learning approaches such as role-play into their classes. But what exactly is role-play? What are its historical and theoretical roots; what distinguishes it from other forms of active, experiential learning methods; and what are its benefits and drawbacks? We address these and related questions in the following sections.

\section{ROLE-PLAY SIMULATIONS}

Role-play simulations share a common lineage with scenario- or problem-based active learning strategies, but they are also unique and distinct from other types of simulations, learning games, and case studies (Errington, 2005). Simulations, as a category of active learning approaches, have a long history in business education as business schools were pioneers in the use of simulations in the classroom (Larreche, 1987). Simulations can be simple paper-and-pencil based activities, such as when students are given the financial data of a simulated company and are evaluated on their ability to analyze it (Anderson and Lawton, 2009), whereas contemporary simulations in the business classroom might often include multimedia supplementation. For instance, Harvard offers a multimedia simulation, "The Startup Game," that shows the dynamics of relationships in entrepreneurial ventures (Assenova and Mollick, 2019). Another multimedia simulation from Harvard, in which a team of climbers enter day-by-day decisions toward their objectives in connection with summiting Mount Everest, has been found to be effective 
in teaching collective decision-making, problem-solving, and teamwork skills (Nichols and Wright, 2015).

Role-play simulations are a specialized type of simulation, distinguished from other simulations by their emphasis on interpersonal interaction. Simulations of all types are generally superior to lectures, for instance, in generating a more interactive learning experience (Montpas, 2004). However, role-plays are distinct from other types of simulation in that the activity is directly built around the interactions among participants. Role-plays require students to generate and express individualized, context-relevant views, anticipating what an individual in their role would likely think and say in practice.

In contrast with simulations, which may or may not incorporate competition with others, active learning through games usually involves a competitive element (Keys and Wolfe, 1990). Games can also be quite expansive and expand even beyond one's school. A classic illustration of an expansive game is the International Collegiate Business Strategy Competition (ICBSC), which has been running since 1964 (Fritzsche et al., 2014). Student participants in the ICBSC engage in a three-month competition where they run their company by making quarterly decisions (e.g., how many units to produce, how much to spend on marketing, how to finance operations, etc.) and compete in an industry against teams from schools throughout the United States and beyond (Fritzsche et al., 2001). Like simulations, games may promote student interaction, particularly if students are participating as part of a team. However, whereas the competitive outcome is the primary focus of games, it is the process of interaction (e.g., how ideas are expressed or conflict is managed) that becomes a primary focus of role-play simulations. This distinction means that role-plays offer a multi-layered option for active learning methods, as the process of a role-play can take many routes before reaching its outcome.

Distinct from simulations or games, case studies have a long history in business education that dates back to their use by faculty at the Harvard Business School and the Kellogg School of Management at Northwestern University in the early twentieth century (Rippin et al., 2002). Cases involve a description of an actual or true-to-life business situation or problem (Booth et al., 2000), requiring that students analyze the situation and identify issues as they would be perceived by specific characters (e.g., a protagonist or members of the leadership team). Case studies are often intended to lead to a class-wide discussion of the issues faced by the characters in the case. The case method was especially influential in 
the movement to professionalize business education and remains popular to this day among business educators (McCarthy and McCarthy, 2006). Importantly, role-plays can be built on or adapted from case studies (e.g., Lund Dean and Forniciari, 2002). Unlike role-play simulations, however, case studies are less personalized in that they generally foster discussion from the class as a whole, rather than student-to-student interaction, and do not bring about a "this is about me" perspective that is fostered with role-play simulations.

\section{Three Aspects of Role-Play Simulations}

Van Ments (1989) describes role-plays as a distinct type of simulation, whereby educators create simplified reproductions of real-world phenomena. Role-plays are built on facilitating interactions between students based on three primary aspects of negotiating social dynamics in organizational life. The first aspect of role-plays is role-taking - the process of adopting, rejecting, or otherwise negotiating the expectations associated with particular roles in organizational life (Stone et al., 2006). Role-plays can facilitate student understanding of the dynamics of role-taking, for instance, by illustrating the pressure of expectations on a supervisor faced with the task of confronting underperforming employees and managing a difficult, but essential, conversation (Stone et al., 2010).

The second aspect of role-plays is role-making, whereby individuals use their own discretion to creatively modify roles to fit the dynamics of the situation (Roberts, 1991). Role-plays can influence students' ability to engage in role-making by facilitating greater situational awareness of the parameters of their role and opportunities for modifying those parameters. For instance, a role-play developed by Phillips and Phillips (2016) based on path-goal leadership theory illustrates how the role of manager can range from providing directives to offering support, depending on the situation and the capabilities and needs of the individual employee.

The third aspect of role-plays is role negotiation, which describes the extent to which roles are negotiated dynamically in social interaction (Bechky, 2006). That is, roles not only vary in the extent to which they are defined and delineated, but they are also enacted in cooperation with others (Kramer, 2010). Role-plays are particularly beneficial for illustrating the dynamics of role negotiation, then, because role identities are actively shaped by and emerge from the evolving discussions among participants (Armstrong, 2003). 


\section{The Flexibility of Role-Plays}

Accordingly, one benefit of role-plays is that they are quite flexible. To illustrate this point, consider an example of converting an in-basket experiential exercise into a role-play. In-basket exercises are simulations in which students are put in the scenario of a manager who is asked to respond (in a constrained amount of time) to a variety of memos, faxes, and voicemails from employees, superiors, and customers (Dukerich et al., 1990). In-basket exercises are great examples of an active, experiential learning activity, but they do not involve direct interaction with other role holders; rather, participants must plan how they would respond as if they were in that situation with imagined counterparts (Connelly et al., 2004).

Nonetheless, it is possible to convert an in-basket exercise into an effective role-play. Greenberg and Rollag (2005) have introduced a clever electronic in-basket exercise with suggestions for how to turn it into a dynamic, multifaceted role-play simulation. In this exercise, students are asked to take on the role of an employee. They receive several emails within a brief period of time and at irregular intervals from superiors, customers, and co-workers to which they are required to respond in a very limited period of time (these emails are pre-crafted and sent by the educator). This exercise can become a full-fledged, electronically mediated role-play when educators not only send out the emails but also respond (as time permits) in real time via email to students' responses. This adaptation, then, turns Greenberg and Rollag's in-basket exercise into a role-play, as a primary learning activity turns to focusing on how students perform in dynamically interacting with and responding to their supervisor, customers, and co-workers.

The illustration of adapting an in-basket exercise into a role-play speaks to the flexibility of role-plays as a reason for their enduring popularity with educators (Lund Dean and Fornaciari, 2002). Although role-plays have been more commonly used in some areas of business education than others, especially management (Caza et al., 2011) and marketing (Taute et al., 2011), they have been used to illustrate a broad array of topics that cut across business disciplines. For example, role-play simulations have the flexibility to illustrate the dilemmas associated with seeking to make ethical decisions in top management teams (Tromley et al., 2014) and to detect fraud in forensic accounting investigations (Janvrin, 2003). Role-plays are well-suited for illustrating the dynamics of cross-cultural negotiation (Smolinski and Kesting, 2012) and commu- 
nicating effectively in a crisis situation (Foote, 2013). For a more detailed overview of how role-plays have been used in business disciplines ranging from accounting and finance to management and marketing, see the annotated bibliography in Chapter 4 .

\section{HISTORICAL ROOTS OF ROLE-PLAYS AS A TEACHING METHOD}

In this section, we describe the historical roots of role-play and discuss several theoretical approaches to understanding the value of role-plays in promoting dynamic, active learning.

\section{Greek Theatre}

The historical roots of role-play as a form of experiential learning go back at least as far as the sixth century $\mathrm{BC}$, to the advent of theatre in ancient Greece (Dugdale, 2008). The concept of acting out the behaviors and words of individuals (i.e., taking a role) was derived from festivals held in the city of Athens to honor Dionysus, the Greek god of wine and fertility (Ley, 2006). According to tradition, around the year 535 $\mathrm{BC}$, a visitor named Thespis leaped onto the back of a wooden cart and recited poetry as if he were playing the roles of the characters whose lines he was reciting - it is from his name that the word "thespian" originates (Dugdale, 2008). Eventually, role-play evolved into a Greek dramaturgy of religious rituals where myths would be reenacted before the community, with individuals acting out the roles of deities (Brockett, 1968).

It is against the backdrop of theatrical role-play that Aristotle emphasized the need for education that went beyond mere memorization (Glisczinski, 2011). Aristotle argued that the ultimate educational goals, such as understanding and the achievement of virtue, were most readily obtained collectively, through interacting with and learning from others in the community (Wittmer, 2004).

\section{Pestalozzi}

Fast-forward nearly two millennia, to the nineteenth-century Romanticism movement in Europe. Johann Heinrich Pestalozzi (1746-1827), a Swiss educator and reformer, drew inspiration from philosophers such as Jean-Jacques Rousseau, a Swiss philosopher of the Enlightenment who lived from 1712 to 1778 . Rousseau argued that learning occurs most 
readily through direct experience (Doyle and Smith, 2007). Pestalozzi, in turn, criticized the then-dominant classroom methods of rote memorization and reading from texts (Takaya, 2003). Instead, he argued that students should learn through a hands-on approach (i.e., learn by doing), which would accomplish practical knowledge that would be directly applicable to the daily affairs of human concerns (Smith, 2011). Pestalozzi's approach emphasized a departure from teaching facts in favor of teaching how to think to resolve problems in practical ways (Ruddy, 2000), an approach that anticipated the utility of role-playing.

\section{Dewey}

In turn, Pestalozzi's work provided inspiration for early twentieth-century educational reformers such as John Dewey in the United States (Smith, 2011). Progressive education movements had taken root throughout the United States in the late nineteenth century, variant in content but sharing the conviction that "children [are] active, not passive, learners," that the education "curriculum needed serious reform to remove the vestiges of medievalism," and "that what usually passed for education was mind-numbing, unnatural, and pernicious, a sin against childhood" (Reese, 2001, p. 2). Dewey (1938) argued that the purpose of education is not to merely convey knowledge, but to share a social experience and integrate the learner into the broader community. Thus, education should not strictly rely on the teacher presenting to the student, but rather should be offered in an active way that encourages students to relate the new information to their previous knowledge (Harrawood et al., 2011). Particularly relevant for understanding the value of role-plays, Dewey rejected any dichotomy between work and play as distinct forms of educational activity, but argued that an optimal combination of seriousness and playfulness represents the idea mental attitude of the educator (Skilbeck, 2017). Dewey's approach, then, supports the idea that interactive and enjoyable methodologies such as role-playing are not incompatible with "serious" learning (Dewey and Bentley, 1949/1991).

\section{Maier}

Arguably, the most influential figure to contribute to the emergence of role plays as a particular type of active learning method is Norman Maier. Maier began his career as an animal psychologist, publishing his doctoral thesis on reasoning in white rats (Maier, 1929). After World 
War II, he shifted his research interests to industrial and organizational psychology (Solem and McKeachie, 1979). Maier worked extensively with corporations and their management challenges, and developed a series of scripted role-plays, drawing from actual situations and stories of employees and managers in the organizations with which he consulted (Maier et al., 1975).

In addition to codifying, through his books, a series of role-plays that business educators could incorporate into their own classes, Maier set the stage for the contemporary use of role-plays in at least two other ways. A pioneer of executive development whose work contributed to the growth of formal executive education programs at major universities, Maier was among the first to use role-plays and other active learning methods with executive-level students (Maier et al., 1957). Additionally, he was among the first researchers and educators to frame the mundane, day-to-day problems of managers and employees as occasions for collaborative, creative problem-solving (Maier, 1971). The use of role-plays to teach managerial skills was consistent with Maier's philosophy that skillful leadership is situational, improvisational, and cumulative in nature, and his work informed the rise of management skills courses in business education (McKnight, 1995).

As the foregoing discussion suggests, role-play simulations have a long and evolving history for facilitating the active engagement of learners. In the next section, we describe theoretical approaches that underpin and inform contemporary applications of role-playing simulations in the business higher education classroom.

\section{THEORETICAL APPROACHES UNDERLYING ROLE-PLAYING}

As a form of active learning, role-playing owes a debt to a variety of modern theories of teaching and learning. These theories tend to focus either on what enables student learning (i.e., how student learning is supported by role-playing) or on the teaching practices of the educator (i.e., the educator's role in structuring the classroom environment to support the benefits of role-playing). These theories are summarized in Table 1.1. 


\section{Table 1.1 Theoretical approaches associated with role-playing}

\begin{tabular}{ll}
\hline How Students Learn & Role of the Educator \\
\hline Experiential Learning Theory (Kolb, 1984) & Mastery Instructional Model (Hunter, 1982) \\
Cultural-Historical Theory (Vygotsky, & Authentic Learning (Herrington and Herrington, \\
1978) & 2006) \\
& Teaching as Making Learning Possible (Ramsden, \\
Two Translations Approach (Rogers, 1961) & 2003) \\
The Tacit Dimension of Learning (Polanyi, & \\
1966) & \\
Practice Theory (Feldman and Orlikowski, \\
2011) \\
$\begin{array}{l}\text { Deep and Surface Learning (Biggs and } \\
\text { Tang, 2007) }\end{array}$ \\
\hline
\end{tabular}

\section{How Students Learn}

\section{Experiential learning theory}

A key figure in experiential learning theory, David Kolb (1984) developed the experiential learning cycle to provide a holistic, longitudinal model of the experiential learning process. The experiential learning cycle draws heavily from experiential learning theorists of the early twentieth century, most notably the work of John Dewey and Kurt Lewin, the latter a luminary from early twentieth-century social psychology. Dewey's influence is reflected in the experiential learning cycle's emphasis on process, rather than the single outcome. Specifically, he argued that educational methodologies should reflect the active, ongoing nature of engaged education, remarking, "The process and goal of education are one and the same thing" (Dewey 1897, p. 79). Optimally, then, engaging active learning methods such as role-plays involves the learner in trial, error, and specific feedback for improvement in trying again (Kolb and Kolb, 2005).

Similarly, Lewin influenced the experiential learning cycle with his insight that directly engaging with and seeking to change a process is the best way to understand a phenomenon (Kolb and Kolb, 2009). Much like Dewey, Lewin suggests that learning should involve learners in integrating their experiences and observations to formulate tentative conceptualizations, which are then challenged by the introduction of new data (Lewin et al., 1939). Lewin's dynamic approach to the learning process is summarized in his quote that "there is nothing so practical as 
a good theory" (cited in Kolb and Kolb, 2005, p. 193), meaning that the helpfulness of a theory is discerned and refined through putting its tenets into practice and observing whether it continues to adequately describe the phenomena of interest.

Kolb's experiential learning cycle follows four stages, which are cyclical and interrelated. The experiential learning cycle does not necessarily begin at any particular point in the cycle; but, in the case of role-plays, the learner ordinarily is first exposed to concrete experiences relevant to the domain of learning. Ideally, that experience engages the learner in reflective observation, whereby the student observes details of the experience and reflects on how they work, how they led to the observed outcome, and so on (Kolb and Kolb, 2005). As opportunities to observe and reflect accumulate, the student begins to generalize concepts (i.e., abstract conceptualization) based on certain principles that they observe across situations. To complete the cycle, learners should challenge their emerging conceptualizations through active experimentation, which involves testing the implications of these tentative conceptualizations in new situations to understand where their understandings are accurate or underspecified (Kolb and Kolb, 2009).

In practice, role-playing supports the experiential learning cycle in two ways. First, role-plays provide students with concrete experiences in a relevant topic, such as ethical dilemmas (McDonald, 2004). Role-plays are particularly useful in classrooms with students of different ages and varying levels of work experience because they provide shared experiences that allow for collective reflection and discussion. Second, role-plays guide students toward confronting their working understandings of phenomena by pushing students to think through the specific details of a situation and respond to unexpected outcomes. That is, it is one thing for a student to outline their plan for meeting with a disgruntled employee, but it is far more insightful to actually role-play that interaction to test where their plans do (and do not) work in practice (Clawson, 2006).

\section{Cultural-historical theory}

Cultural-historical theory, based on the work of Lev Vygotsky, offers another perspective on the value of role-play in the learning process. Vygotsky's theorizing initially focused on learner development in early childhood, but has since been extended to apply to adult learners (e.g., Venne and Coleman, 2010). A key premise of cultural-historical theory is that play and imagination (e.g., make-believe) are not antithetical to 
serious learning, but in fact promote a holistic learning that integrates cognitive, social, and emotional development (Smidt, 2009). Vygotsky (1978) does not view play as an escape from rules and social norms, but rather as an opportunity to step outside one's self and take on roles and responsibilities that stretch learners beyond their current capacity. Specifically, he defines play in terms of a semi-structured process of creating an imaginary situation, taking on and acting out roles, and adhering to a set of rules determined by role requirements (Bodrova and Leong, 2007).

From the perspective of cultural-historical theory, two dimensions of role-plays make them particularly useful as a method of active learning in the business classroom. First, role-playing is sociodramatic, which means that effectively playing one's own role requires cooperating with and accounting for the role requirements of others (Karpov, 2003). Role-playing can thus facilitate greater social awareness, self-regulation, and perspective-taking - the ability to better understand the world from the perspective of others (Bodrova and Leong, 2007). In fact, the promise of role-playing in business education was initially framed in terms of improving social relations among employees and between labor and management (Maier, 1952, pp. 87-140), as well as to gain a broader understanding of the social problems confronting organizations (Chesler and Fox, 1966).

Second, role-playing is typically scaffolded (Venne and Coleman, 2010), which means that learners are provided with cognitive and emotional support as they navigate their unfamiliar role. Vygotsky suggested that, at a given point in their development, there are things that students can do on their own and things that they cannot do; but there are also things that students could do, but not yet on their own. Thus, the educator benefits the student's learning by mediating, but ideally with less and less direct involvement as the student becomes more and more skillful (Scharer, 2017). For instance, early in a semester, an educator might actually take on one of the roles in a role-play (e.g., play the role of a manager exhibiting supportive communication) opposite the student to demonstrate what skillful performance in that role might look like. As students gain more experience with role-plays, the educator becomes more of an observer and a coach, providing encouragement and feedback. Ideally, educators tailor their involvement to create a "zone of proximal development" whereby learners are stretched just beyond their existing knowledge and skills to promote continued engagement and learning (Vygotsky, 1978). 


\section{Two translations approach}

Carl Rogers was a prominent psychologist, known for his role in steering the 'humanistic turn' in psychology in the middle of the twentieth century and as an advocate of a client-centered approach in his psychology practice (Thorne and Sanders, 2012). Rogers' learner-centered approach to teaching was an extension of his psychology practice, informed by a belief that true learning must be a process of self-discovery, facilitated by the educator but engaged by the student (Smith, 2011). Thus, Rogers put a premium on focusing on the lived experience of the individual:

Experience is, for me, the highest authority. The touchstone of validity is my own experience. No other person's ideas, and none of my own ideas, are as authoritative as my experience. It is to experience that I must return again and again, to discover a closer approximation to truth as it is in the process of becoming in me. (Rogers, 1961, p. 24)

Importantly, Rogers emphasized the value of empathic understanding, whereby students are able to put themselves in the place of others to imagine the experience of the world from that person's perspective and in terms of that person's feelings (Elliot et al., 2011). Learning from one's own experiences and the experiences of others is difficult to do in isolation or apart from interaction with others; thus, Rogers advocated for collaborative educational practices such as role-play that incorporate interaction with and active learning from one's peers in the classroom (Bohart and Byock, 2005).

Rogers' two translations approach distinguishes between internal congruency, the overlap between individuals' thoughts and what they experience (i.e., emotions and feelings), and external congruency, the degree to which individuals' thoughts are consistent with their behaviors (Clawson, 2006). Role-plays can be a helpful method of identifying and confronting both internal and external incongruence. For instance, the vocabulary of professionalism and related aspects of work may privilege rational thought and discourage the recognition of feelings and experiences (Cheney and Ashcraft, 2007). Educators can redirect attention to the overlap between what one thinks and experiences by asking questions in the debrief that follows the role-play, for instance, about the experience of participation (e.g., "How did you feel when she said that - or when you were passed over for the promotion?").

Perhaps more crucially, role-plays can serve as an incisive tool for illustrating what Rogers describes as "external incongruences." 
Role-plays require that students translate mental plans into actual words and actions, much as students would actually have to do in organizations (Clawson, 2006). In role-plays, students are confronted with situations where their intentions may not be accurately manifested in their words or actions (e.g., "That's not what I meant to say"). Thus, role-plays offer a remedy to students' beliefs that they can learn as much about the behavior skills required of participating and leading in organizations by sitting back and observing rather than actively participating (Clawson, 2006).

\section{The tacit dimension of learning}

Michael Polanyi was a twentieth-century scientist-turned-philosopher whose work gave significant attention to describing the tacit aspects of learning and knowledge. Polanyi described a fundamental dilemma in the transfer of knowledge in his book The Tacit Dimension (1966, p. 4):

I shall reconsider human knowledge by starting from the fact that we can know more than we can tell. This fact seems obvious enough; but it is not easy to say exactly what it means. Take an example. We know a person's face and can recognize it among a thousand, indeed among a million. Yet we usually cannot tell how we recognize a face we know. So most of this knowledge cannot be put into words.

As McKnight (1995) describes, an important insight from Polanyi's theorizing is that certain types of knowledge that are highly contextual, skills-based, and particularly relevant to business educators - such as interpersonal skills, managing conflict, and supportive communication - are holistic in nature. So, for instance, the receptivity of an employee to feedback from a manager is a function not only of the content of the message but also of the manager's facial expressions, vocal inflections, nervous glances at the clock or actions projecting self-assuredness, and the like (McKnight, 1991). Moreover, employees' perceptions of their manager are not isolated to single instances so much as the accumulation of the manager's behaviors over time.

The knowledge of what constitutes a skillful performance interpersonally is so subtle and contextual that it is virtually impossible to adequately convey through traditional lecture. The analog would be telling someone how to drive a car or reading instructions on how to drive from a book, which is far less effective than an education model of giving someone controlled experiences behind the wheel with an observer who provides them with real-time feedback on their performance (McKnight, 1995). Role-plays, then, serve as an essential component of transferring tacit 
knowledge because they provide concrete experiences through which students may practice skills under the watchful eye of an educator and with opportunities for feedback from their peers. Role-plays allow educators to become more akin to coaches and able to deliver more personalized, real-time feedback as they observe students' performance (McKnight, 1995).

\section{Practice theory}

Related to the tacit dimension of learning, practice theory embodies a set of theories developed over the past three decades associated with the so-called "practice turn" in the study of businesses and organizations (Whittington, 2011). The practice turn refers to a shift in conceptualizing key business concepts in terms of what people do - e.g., rather than having an organizational strategy, strategy is something that people do (Hambrick, 2004). Practice theory is a distinctive perspective that systematically examines how understandings, concepts, and everyday activities and practices dynamically unfold in relation to one another in time (Nicolini, 2012). For instance, through a practice lens, the elements of day-to-day life in organizations (e.g., identities, concepts, institutions, power relationships, even resources) take on meaning through how they are used in relation to other practices (Feldman and Orlikowski, 2011). That is, these elements do not exist in abstract, but their existence in organizations is co-created through the words and actions of organizational actors in practice (Østerlund and Carlile, 2005).

Although relatively new in its application to teaching and learning, practice theory informs active learning approaches such as role-play by emphasizing that everyday actions, as they are carried out day-to-day, are consequential in producing and reproducing the structural contours of work relationships (Feldman and Worline, 2016). In other words, the focus of practice theory is not that individuals engage in certain behaviors (e.g., active listening, communication, etc.). Rather, the focus is on how students carry out those behaviors in practice (Feldman and Orlikowski, 2011).

Practice theory provides robust justification for the use of role-play, then, by emphasizing that the cumulative execution of behaviors in practice makes or breaks the effectiveness of managers. For instance, students may learn that supportive communication should separate the person from the problem; but the real test of their communication effectiveness is their ability, in the heat of the moment, to talk about a breakdown in their relationship rather than making "you" accusations - e.g., "You are 
insensitive" (Carlopio et al., 2012). Role-plays are valuable because they can recreate some degree of the "heat of the moment" to show students how they can enact supportive communication in practice (Clawson, 2006).

Finally, practice theory supports the place of role-plays in business education by emphasizing how individuals vary their information processing and behavioral responses based on the nature of their situation (Kudesia, 2019). Put differently, practice theory emphasizes that individuals are mindful agents who can change their responses to the situation at hand, but are able to do so only to the extent that they adjust their information processing to account for specific features of the situation e.g., perceiving that an employee seems particularly upset and adjusting one's approach to try to understand why (Bandura, 2006). Role-play excels as an active learning method that provides students with practice in actively monitoring their environment and adjusting the processing of information to respond flexibly to their situation, a critical competency for managers (Whetten and Cameron, 2011).

\section{Deep and surface learning}

A final theoretical perspective relevant to our discussion of how students learn is Biggs and Tang's (2007) model of deep and surface learning. Biggs and Tang suggest that students can engage in a surface approach to learning, which is characterized by exerting the minimum amount of cognitive effort and acquiring what they perceive to be a sufficient level of knowledge (Hall et al., 2004). So, for instance, surface approaches to learning might manifest in memorizing facts rather than engaging to really understand the material (Biggs and Moore, 1993).

Surface approaches to learning are often extrinsically motivated, driven by the student's goal to do just enough to pass the class, get the diploma, etc. (Booth et al., 1999). In contrast, a deep approach to learning involves approaching learning with the intention to understand and apply the material (Biggs and Moore, 1993). It is not surprising, then, that deep approaches to learning have been associated with better retention and transfer of knowledge, among other learning outcomes (Ramsden, 2003).

The distinction between deep and surface approaches to learning is helpful for understanding a motivational dimension of how role-play can facilitate student learning. Specifically, role-plays tend to demand a deeper level of student engagement than traditional lectures because students are put in a position to immediately apply what they have learned to respond to their counterpart (Clawson, 2006). Application, in 
turn, is likely to promote higher- and deeper-level understanding than simple comprehension or memorization (Bloom, 1956). These effects can be optimized when educators involve students in the plans for active learning via role-plays, providing them with motivation to engage with course topics as preparation.

\section{The Role of the Educator}

In addition to approaches that focus on how students learn, several theories explore the role of the educator in crafting and effectively deploying active learning exercises such as role-plays. Although she referred primarily to educators in K-12 education (ages 4-6 to 17-19), Madeline Hunter's description of the importance of the role of the educator is worth repeating in the context of business education as well:

If your life depended on a student's successful learning and you could prescribe excellence in only one school variable, on which one would you bet your life? School organization? School building? A particular program? Books? Materials? Pupil-teacher ratio? Classmates? Amount of money spent? Or the teacher? The majority of answers to that question would result, without any hesitation, in a loud chorus of "Teacher!" Yet we continue to spend millions of dollars on those things we don't believe have as telling an impact. (Hunter, 1982, p. 162)

We share the belief that the success of role-play simulations and other approaches to active learning depend to a great degree on how educators craft, organize, introduce, execute, and debrief the role-play (Lund Dean and Forniciari, 2002), and we will cover specific ideas and suggestions for running role-plays in Chapter 2. In this section, however, we briefly discuss several theoretical perspectives on the role of the educator in facilitating student learning from role-plays and other forms of active learning.

\section{Hunter model of mastery teaching}

The Hunter model is a helpful theoretical perspective in understanding the role of the educator in facilitating student learning, as Hunter was among the foremost advocates of a teaching philosophy that centers educator attention on student learning (Heath, 2003). The Hunter model starts from the premise that educators make three categories of choices in the instructional process. In addition to choices about content (i.e., what to teach), educators make decisions about what they will do to facilitate 
and escalate student learning (i.e., teaching behavior choices) and how they will know that students are learning the material (learning behavior choices) (Hunter, 1982).

Although Hunter (1982) does not specifically discuss role-plays in the college classroom, her model has implications for understanding how using role-plays can foster student learning. For instance, she is concerned with student motivation to learn, recognizing that some students are unready or unwilling to engage in the classroom. Therefore, the Hunter model frames motivation from multiple angles. On the one hand, Hunter suggests that educators need to find ways to raise the level of their students' concern about learning, whether through making the task more salient and apparently meaningful, making individual students' efforts more identifiable and public, or similar tactics (Hunter, 2004). On the other hand, she also recommends creating a positive "feeling tone" in the classroom by recognizing student achievement and celebrating student efforts (Hunter, 1984).

Role-plays have the potential to both raise the level of students' concern about their learning and contribute to creating a positive feeling tone in the classroom. Role-plays tend to raise the level of students' concern because students know they not only have to read the materials and grasp the concepts, but that they will also have to act out their role in the presence of a peer (and potentially the educator). However, role-plays can also contribute to generating a positive feeling tone in the classroom as students vicariously feed off the energy and engagement of their peers (Frederick, 1987).

In addition to student motivation to learn, the Hunter model of mastery teaching focuses on the role of the educator in ensuring that the student is truly absorbing the material. For instance, Hunter (1984) emphasizes how educators should "check for understanding" to ensure that students are fully comprehending and able to apply the material they are being taught. According to Hunter (2004, p. 98), "The difference in knowing how something should be done and being able to do it is the quantum leap in learning."

Role-playing provides a natural opportunity to check for student understanding. Specifically, role-plays prevent students from simply believing that they know what to do, by putting them in a position to demonstrate and apply their knowledge in practice - and to see where they succeeded and where they fell short (Clawson, 2006). Role-playing, then, provides a helpful alternative means of evaluating the quality of student learning. 


\section{Authentic learning theory}

Herrington and Herrington (2006) describe a scene where students are engaged in challenging activities that require collaboration and inquiry, which require sustained, intensive effort, and that reflect the work in which students will engage in their professions. However, Laurel (1993) argues that too often, students face a reality of learning in large lecture halls with a "sage on the stage" in front, transmitting knowledge in small chunks for learners to passively receive and perhaps memorize. The heart of the researchers' critiques of traditional lectures is their "inauthenticity" in the sense of not facilitating learning that reflects the situated, applied, collaborative nature of work in organizations (Brown et al., 1989; Herrington et al., 2014).

Authentic learning, by contrast, is characterized by tasks with real-world relevance which present complex activities that must be completed over a period of time (Herrington et al., 2014). An authentic learning context presents realistic problems that capture the complexity of the dilemmas of real life in a holistic manner, rather than in organized, bite-sized weekly lectures and tutorials (Herrington and Herrington, 2006). Role-play has been cited as an example of the type of active learning that supports a more complex, authentic learning environment (Reeves et al., 2002). In particular, role-plays present problems holistically and push students to sort through multiple, often ill-defined issues with no single "correct" answer to engage in skillful performance, all of which are hallmarks of what researchers describe as authentic approaches to teaching and learning (Herrington et al., 2014).

\section{Teaching is making learning possible}

The final theoretical approach informing the role of the educator in facilitating role-plays - teaching is making learning possible - draws from the work of Ramsden (2003). A thesis of Ramsden's work is that the increase in expectations of university educators from policymakers, activists, parents, private companies, and other societal stakeholders means that it is not enough for educators to simply deliver knowledge and hope that students absorb and retain it. To paraphrase mathematician and philosopher A. N. Whitehead, students "cannot be wise without some basis of knowledge; but [they] may easily acquire knowledge and remain bare of wisdom" (Ramsden, 2003, p. 3).

Consistent with Hunter (1982) and Herrington and Herrington (2006), Ramsden's perspective supports the use of role-plays and other active learning methods as proactive approaches to facilitating student learning. 
Specifically, he argues for contingent approaches to teaching that provide instructors with the ability to customize activities to the specific needs of a class or even a subset of students. Role-plays and other active learning approaches are especially useful tools within Ramsden's framework that foster the kind of flexible approach that accompanies more dynamic student learning strategies (Fry et al., 2008).

To summarize, the value of role-plays as an active learning method is situated squarely in an array of theories on teaching and learning. From offering concrete experiences of holistic problems to forcing students to confront inconsistencies in standards or expectations, and from helping to transfer tacit knowledge and develop social skills to generating deeper levels of engagement, role-play simulations are a valuable and theoretically grounded tool for business educators across business disciplines.

\section{A DEEPER VIEW OF THE BENEFITS OF ROLE-PLAYS}

Thus far, we have described the theoretical and historical background of role-playing as an active learning approach for business educators, and have provided a variety of examples of how role-plays have been employed across business disciplines along with recent theories of teaching and learning that ground the benefits of role-plays for student learning. To further establish the usefulness of role-plays as a teaching tool, we now consolidate and summarize many of the benefits of role-plays described previously in terms of three types of student learning outcome.

In their research, Christensen and Menzel (1998) distinguish different types of student learning outcome that educators may influence: cognitive, behavioral, and affective. Cognitive learning outcomes refer to the comprehension of knowledge and thought processes that are affected by instruction or training (Kraiger et al., 1993), and hence specifically refer to the acquisition of knowledge. They are often closely related to "general cognitive ability" that is the focus of assessments of IQ and other paper-and-pencil evaluations of knowledge - e.g., the SAT (standard U.S. college admissions test) or the American College Test (ACT), written exams, etc. (Koenig et al., 2008). In contrast, behavioral learning outcomes refer to the skillful enactment of behaviors in practice, including physical or verbal tasks (Edwards et al., 2009). For instance, engaging in supportive communication to resolve a problem between employees would be an example of a behavioral learning outcome for students who have managerial aspirations (McKnight, 1995). Finally, 
affective learning outcomes refer to learning that affects student beliefs, attitudes, or feelings about themselves and their ability to succeed in a given domain (Kraiger et al., 1993). For instance, affective learning outcomes might include greater understanding of and tolerance toward the positions and beliefs of other parties (Rees and Sondak, 2015), or enabling student motivation through increasing students' self-efficacy (Kraiger et al., 1993).

Table 1.2 highlights these three types of student learning outcome (cognitive, behavioral, or affective) and points to where they are associated with particular benefits of role-plays.

\section{Benefit \#1: Role-Plays Can Increase Student Engagement}

As discussed earlier, increased student engagement is one of the key benefits, and primary motives, for the use of role-plays and other methods of active learning (Clawson, 2006). Increased student engagement associated with role-plays has a particular impact on cognitive and affective student learning outcomes, both within a given class and more broadly for their careers. Within the classroom, role-plays that promote student engagement can facilitate cognitive outcomes such as greater comprehension and retention of the material, at least partly by effectively managing students' attention spans (Braxton et al., 2000). Outside the classroom, the effects of role-plays on student engagement are particularly strong on affective student learning outcomes. Specifically, we note the impact of active learning strategies such as role-plays on increasing student commitment to the institution, which can, in turn, yield improved year-to-year student retention rates (Kuh et al., 2006; Prince, 2004).

\section{Benefit \#2: Role-Plays Can Foster Behavioral Change}

Drawing inspiration from Lewin's (1947) three-step model for creating change, role-plays are a useful tool for enabling students to understand and engage in behavioral change. According to Lewin, the most critical, and difficult, step in creating change is "unfreezing," or establishing why change is needed and providing a blueprint for how it can be accomplished. Role-plays are useful for fostering behavioral change through their impact on cognitive, behavioral, and affective student learning outcomes. For instance, role-plays affect cognitive outcomes surrounding behavioral change because, rather than educators simply telling students to change a behavior (as with traditional lecture), role-plays allow stu- 


\section{Table 1.2 Overview of the benefits of role-plays in terms of student learning outcomes}

\begin{tabular}{|c|c|c|c|}
\hline $\begin{array}{l}\text { Benefits of } \\
\text { Role-Plays }\end{array}$ & $\begin{array}{l}\text { Cognitive Learning } \\
\text { Outcomes }\end{array}$ & $\begin{array}{l}\text { Behavioral Learning } \\
\text { Outcomes }\end{array}$ & $\begin{array}{l}\text { Affective Learning } \\
\text { Outcomes }\end{array}$ \\
\hline Student engagement & $\begin{array}{l}\text { Enhanced } \\
\text { comprehension and } \\
\text { retention of the material }\end{array}$ & & $\begin{array}{l}\text { Greater commitment } \\
\text { to the educational } \\
\text { institution and } \\
\text { year-to-year retention }\end{array}$ \\
\hline Behavioral change & $\begin{array}{l}\text { Illustrates the } \\
\text { underlying need - i.e., } \\
\text { why change is needed) } \\
\text { ("head knowledge") }\end{array}$ & $\begin{array}{l}\text { Demonstrates how } \\
\text { more functional } \\
\text { behaviors work (or } \\
\text { don't work) in practice } \\
\text { ("hands knowledge") }\end{array}$ & $\begin{array}{l}\text { Provides insight } \\
\text { into how to connect } \\
\text { with others and } \\
\text { why behavioral } \\
\text { change is personally } \\
\text { meaningful ("heart } \\
\text { knowledge") }\end{array}$ \\
\hline Higher-order thinking & $\begin{array}{l}\text { Pushes students } \\
\text { to move beyond } \\
\text { comprehension to } \\
\text { application and } \\
\text { evaluation }\end{array}$ & $\begin{array}{l}\text { Promotes personal } \\
\text { skill development } \\
\text { through emphasis on } \\
\text { application }\end{array}$ & \\
\hline $\begin{array}{l}\text { Accesses multiple } \\
\text { intelligences }\end{array}$ & $\begin{array}{l}\text { Allows students to } \\
\text { demonstrate other } \\
\text { forms of cognitive } \\
\text { intelligence, such as } \\
\text { the ability to think on } \\
\text { one's feet }\end{array}$ & $\begin{array}{l}\text { Allows students } \\
\text { to demonstrate } \\
\text { interpersonal } \\
\text { intelligence (e.g., } \\
\text { intuitive ability to } \\
\text { read and respond } \\
\text { empathetically to } \\
\text { others) }\end{array}$ & $\begin{array}{l}\text { Allows students } \\
\text { to demonstrate } \\
\text { emotional } \\
\text { intelligence }\end{array}$ \\
\hline Assessment & & $\begin{array}{l}\text { Enables evaluation } \\
\text { of behaviors and } \\
\text { application of } \\
\text { skills beyond } \\
\text { pencil-and-paper } \\
\text { assessments }\end{array}$ & \\
\hline Perspective taking & $\begin{array}{l}\text { Pushes students to } \\
\text { think about what others } \\
\text { must be thinking in } \\
\text { a particular situation }\end{array}$ & $\begin{array}{l}\text { Enables students to see } \\
\text { how their behavior is } \\
\text { interpreted by others }\end{array}$ & $\begin{array}{l}\text { Pushes students to } \\
\text { think about what } \\
\text { others must be } \\
\text { feeling and why they } \\
\text { respond as they do }\end{array}$ \\
\hline
\end{tabular}




\begin{tabular}{|c|c|c|c|}
\hline $\begin{array}{l}\text { Benefits of } \\
\text { Role-Plays }\end{array}$ & $\begin{array}{l}\text { Cognitive Learning } \\
\text { Outcomes }\end{array}$ & $\begin{array}{l}\text { Behavioral Learning } \\
\text { Outcomes }\end{array}$ & $\begin{array}{l}\text { Affective Learning } \\
\text { Outcomes }\end{array}$ \\
\hline $\begin{array}{l}\text { Reflection and } \\
\text { personalization of } \\
\text { learning }\end{array}$ & $\begin{array}{l}\text { Encourages students } \\
\text { to reflect on what they } \\
\text { have observed and } \\
\text { draw inferences to } \\
\text { generalized principles }\end{array}$ & $\begin{array}{l}\text { Enables students to } \\
\text { calibrate and customize } \\
\text { their behavior based } \\
\text { on the feedback they } \\
\text { receive from others }\end{array}$ & $\begin{array}{l}\text { Motivates students } \\
\text { to reflect on what } \\
\text { approaches most } \\
\text { resonate with them } \\
\text { emotionally and with } \\
\text { their identities }\end{array}$ \\
\hline $\begin{array}{l}\text { Build student } \\
\text { self-efficacy }\end{array}$ & $\begin{array}{l}\text { Serves as a "mastery } \\
\text { experience" that shows } \\
\text { that the student can } \\
\text { succeed at the task }\end{array}$ & $\begin{array}{l}\text { Serves as a "modeling } \\
\text { experience" in which } \\
\text { students model their } \\
\text { behavior on how others } \\
\text { successfully complete } \\
\text { a task/activity }\end{array}$ & $\begin{array}{l}\text { Offers opportunities } \\
\text { for "verbal } \\
\text { persuasion" and } \\
\text { related forms of } \\
\text { encouragement and } \\
\text { reinforcement }\end{array}$ \\
\hline
\end{tabular}

dents to experience the situation more directly, and thus show them why change is needed, or what McKnight (1995) labels "head knowledge." Similarly, role-plays influence behavioral outcomes by providing students with opportunities to rehearse how they would engage in a different behavior in a relatively controlled, low-risk classroom environment, what McKnight calls "hands knowledge." Finally, role-plays foster behavioral change by showing students how the changed behavior improves their interactions with others and improves their own lives - i.e., "heart knowledge" (McKnight, 1995), indicating a change in affective outcomes.

\section{Benefit \#3: Role-Plays Can Enable Higher-Order Student Thinking}

Bloom's Taxonomy describes a hierarchical model of student learning outcomes that ascends based on increasingly higher-order student thinking (Bloom, 1956). For instance, an introductory class with novice learners may focus exclusively on students' acquisition of knowledge and comprehension of concepts, whereas more advanced classes would bring about more sophisticated, higher-order learning outcomes, including the ability to apply the knowledge to actual situations as well as the ability to analyze, synthesize, and evaluate information (Athanassiou et al., 2003).

Role-plays are valuable learning tools for facilitating higher-order thinking. Specifically, role-play influences cognitive learning outcomes by pushing students to apply concepts or principles (e.g., the principles of supportive communication) to a simulated real-life situation such as delivering feedback to a disgruntled employee (Pavey and Donoghue, 
2003). Similarly, the emphasis of role-plays on application promotes behavioral learning outcomes as it is more difficult for students to settle for mere knowledge of a skill when they have to actively demonstrate the skill via role-play. Rather, role-plays push them to understand how to carry out the skill in practice (Clawson, 2006).

\section{Benefit \#4: Role-Plays Access Multiple Intelligences}

Harvard educational psychologist Howard Gardner popularized the concept of multiple intelligences, whereby he suggests that traditional assessments of knowledge (e.g., paper-and-pencil exams) only capture a narrow component of intelligence. Instead, Gardner (2011) argues that there are eight different types of intelligence that should be accounted for in order to understand the broad range of human potential in students. Beyond traditional measures of cognitive intelligence (i.e., IQ), Gardner advocates for also recognizing intelligences ranging from linguistic ("word smart") to intrapersonal ("self-smart") to interpersonal ("people smart").

Role-playing is complementary to the perspective of multiple intelligences because it engages students holistically to apply skills that are embodied and multifaceted (McKnight, 1995). For instance, a role-play where a student is in the role of a customer service representative dealing with an unhappy customer not only requires knowledge of company policy to address the source of dissatisfaction (a cognitive learning outcome), but also a variety of interpersonal skills (a behavioral learning outcome). In such a situation, students need to cultivate their ability to read the non-verbal signals of the customer, their ability to speak calmly to mitigate the customer's anger, and their ability to "read" the situation quickly to recognize whether the customer's anger is genuine or strategic (an affective learning outcome). Thus, role-plays can engage students in the development of multiple intelligences that cut across cognitive, behavioral, and affective learning outcomes.

\section{Benefit \#5: Role-Playing Can Enable Broader, Multi-Dimensional Methods of Assessment}

Constructing assessment instruments and protocols to accurately and completely evaluate knowledge and skills in practice is a perpetual challenge for business educators (Beard et al., 2008). However, employers are demanding that students be able to apply their skills in practice, 
particularly so-called "soft skills" such as communication, conflict management, and the ability to work effectively in groups (Robles, 2012). Thus, business education accrediting agencies (e.g., AACSB) and others have placed emphasis on broadly assessing a range of student skills and knowledge (Martell, 2007).

Role-playing provides a robust, holistic method of assessing student skills (Errington, 1997). In particular, role-playing is useful for assessing behavioral learning outcomes that would be difficult to evaluate via a paper-and-pencil exam, including skillful performance of critical managerial tasks such as delivering feedback to employees, working with clients, interacting with customers, collaborating as part of a team to complete tasks or solve multifaceted problems, etc. Thus, role-playing can be used as an evaluation tool to complement traditional evaluations of knowledge (McKnight, 1995) and to close the loop in determining the extent to which students can execute behavioral skills in practice.

\section{Benefit \#6: Role-Plays Can Facilitate Perspective Taking}

The concept of perspective taking is built on work by the developmental psychologist Jean Piaget. Piaget (1972) suggested that perspective taking, which involves imagining the world from the point of view of someone else, is one of the most critical and challenging skills related to human development. However, individuals often fail to exert the effort to perceive the world from the perspective of others (Galinsky et al., 2008), in part because imagining the world from the perspective of others requires effortful cognition and higher-order thinking. In fact, researchers find that we are often systematically oblivious to how inaccurately we perceive the perspectives of others (Galinsky et al., 2006). Accordingly, individuals may be unfamiliar with how to take the perspective of others, they may forget to consider the other person's perspective, or some combination of both (Gerace et al., 2013).

Role-playing can facilitate cognitive learning outcomes associated with perspective taking because it tasks students with imagining how they would think and behave if they were the person in the role they are taking. Role-playing can also promote behavioral learning outcomes associated with students' ability to take the perspective of others because students can try out what they believe the other person would say or do and receive immediate feedback (e.g., their peers' reactions or the educator's feedback). Additionally, role-playing has the potential to facilitate not only the cognitive (i.e., accurate anticipation of what others think) 
and behavioral (i.e., this is how others interpreted my behavior, irrespective of how I intended it), but also the affective aspects of perspective taking (i.e., accurate understandings of what others are likely to feel). This benefit can be promoted when role-plays involve an exchange of roles such that a student ultimately plays both "sides" in an exchange, thus experiencing the perspective of each.

\section{Benefit \#7: Role-Plays Can Promote Reflection and Personalization of Learning}

Kolb (1984) suggests that one of the essential benefits of interactive, experiential learning methodologies is their ability to foster individual reflection on experiences. Reflection is a pivotal activity in the learning process because it connects observations of data from concrete experiences to the generalization of principles from abstract conceptualization, a key cognitive learning outcome (Kolb and Kolb, 2005). In turn, learning becomes personalized when students apply generalized principles (e.g., concepts), receive feedback in terms of others' responses to the application of those principles, and then calibrate and adjust their behaviors to determine what yields the best outcomes (a behavioral learning outcome) and what feels the most comfortable and resonates most with their identity and beliefs (an affective learning outcome (Petriglieri et al., 2011).

However, students are sometimes quite reluctant to engage in reflection (Lopate, 2005). Role-plays can motivate reflection by students in a variety of ways. In many cases, the educator can prompt the reflection through well-designed debriefing questions, especially when higher-order skills have been fostered via other activities. Pointing to specific tactics taken by one group, contrasted with another, may provide a valuable prompt for reflection, for example. However, even in instances when role-plays turn out unexpectedly poorly, students are able to see the inadequacy of tactics that they otherwise may have believed to be appropriate. Negative emotions from disappointing feedback or insufficient solutions can sometimes increase student engagement and motivation by making shortcomings vivid and apparent, and thereby raising the level of students' concern (Hunter, 1982).

\section{Benefit \#8: Role-Plays Can Build Students' Self-Efficacy}

Role-playing has the potential to increase students' self-efficacy. Self-efficacy refers to the degree to which individuals believe that 
they have the capability to perform successfully in a given task domain (Bandura, 1977). Role-plays have the potential to facilitate business students' self-efficacy in several ways (Karatay and Gürarslan Baş, 2017). For instance, Vygotsky, an important figure in developmental psychology whose work we discussed earlier, argues that optimal learning occurs when students are stretched out of their comfort zones but simultaneously provided with enough support that they are able to successfully complete a task (Vygotsky, 1978). Role-playing, then, can serve as a "scaffold," a structured opportunity for practice that gives students an opportunity to succeed at a task that may be a little beyond their immediate capacity. Students' success in the role-play may serve as a mastery experience that builds their self-efficacy (i.e., a cognitive learning outcome, "I've done this before!") when presented with a similar task in the future (Bandura, 2010).

Beyond providing students with safe opportunities to practice their skills in a relatively low-stakes environment (Richardson and Kleiner 1992), role-plays provide more vicarious behavioral learning outcomes. Specifically, role-plays with peers expose students to opportunities to observe others and model their behavior on how others have successfully completed a task (Van Dinther et al., 2011). Additionally, role-plays can foster affective learning outcomes associated with increased self-efficacy as students can receive positive reinforcement (i.e., "verbal persuasion") from educators and peers (Bandura, 2010). The value of this type of encouragement and support should not be overlooked because it sets the stage for students' willingness to engage in more intensive and potentially socially risky active learning activities later in the semester (Lund Dean and Jolly, 2012).

Together, these benefits of role-plays as a method of active learning suggest not only that they are valuable tools in the modern business classroom, but also that they can be used in myriad ways to foster student development. Beyond the limited notion of transferring knowledge, role-plays allow students to develop cognitive skills to enhance their comprehension of course principles, advance in their behavioral knowledge such that they can better link action to desired results, and mature in affective knowledge to optimize their current and future interaction with others. 


\section{POTENTIAL DRAWBACKS OF ROLE-PLAYS}

In this chapter and throughout this volume, our focus is overwhelmingly on the value and benefits of role-playing as an experiential learning method. However, before proceeding, it is important that we also acknowledge the potential drawbacks of using role-plays in teaching business disciplines. As we have described, role-playing is a powerful method of learning because it makes the consequences of one's actions and the actions of others visible and relevant (van Ments, 1989). Role-plays thus provide vivid feedback about the effects and consequences of one's actions on oneself and others (Daly et al., 2009).

However, the vividness and immediacy of feedback that often facilitates learning can also hinder learning when it leads to intense emotional reactions (Vince, 1998). For example, the specific situation reenacted in a role-play may lead a student to revisit a similar, painful past experience and suffer those negative emotions all over again (Taylor, 2018). Separately, students - particularly those who are shy or more reserved - may react negatively or defensively to being asked to participate in role-plays (Lund Dean and Jolly, 2012). In other cases, students may experience performance anxiety or frustration with role-plays, particularly if they are engaged with a counterpart who is not earnestly playing his or her role (Kettula and Berghäll, 2013). Students may vary in how seriously they take their roles, or over-dramatize their roles at the expense of the learning objectives (Westrup and Planander, 2013).

Educators should also be aware that role-playing can create uncomfortable situations for themselves or adverse reactions. For instance, giving students the opportunity to engage in role-play may lead educators to experience a loss of control over student learning (Moizer et al., 2009). Educators can feel anxiety about surrendering a degree of control over student learning, but also fear of personal failure if the role-play does not lead to expected learning outcomes (Tomkins and Ulus, 2016). Both the beauty and the risk of role-plays is that they are dynamic and unpredictable; the same role-play in two different classes may generate dramatically different outcomes that are impossible to anticipate with certainty (Gilmore and Anderson, 2011). In short, educators should be aware that role-plays have the potential to generate anxiety and strong emotional responses not only in students but also in themselves - and should therefore seek to develop the skills and competence to facilitate role-plays effectively. 
In Chapter 2, we discuss in more detail various tactics and strategies that educators can use to manage or mitigate some of the anxiety or negative responses that students (and educators) may experience in connection with role-plays. However, as a general consideration, it is important that, in deciding whether to employ and how to craft role-plays for a particular topic, educators take care to understand their desired learning objectives of the activity. It is true that role-plays on some topics are more likely to elicit negative responses than others. For instance, a role-play may illustrate or raise topics that are taboo or sensitive, and thus unlikely to be discussed candidly (i.e., "undiscussables," Baker, 2004). In turn, increasing societal pressures toward political correctness may make students reluctant to fully engage in role-plays and discussions about diversity and related subjects (Avery and Steingard, 2008). Additionally, the way that role-plays are designed matters, as certain role-plays may be constructed such that they invoke, perhaps purposely, stereotypes that some students find offensive (Sogunro, 2004).

It is essential, then, to start with the desired learning objectives of a particular class session in mind so that educators can decide whether there are any features of a given role-play that are likely to detract from the essential take-aways of the class session. We emphasize that this does not mean that educators should necessarily shy away from role-plays on potentially sensitive topics. In fact, concerns about political correctness and avoiding offense throughout higher education may prevent students from hearing competing worldviews and understanding that racism, sexism, and ageism are, in fact, persistent problems in organizations (Barreto and Ellemers, 2005). Discussing politically and socially sensitive topics is possible if educators have laid groundwork for a "zone of understanding," a set of ground rules, enforced by the educator, where speaking with candor and actively listening are normative (Avery and Steingard, 2008). We will discuss tactics for creating a zone of understanding in Chapter 2. However, it is also important for educators to gauge their own level of comfort and recognize that it is okay to "opt out" of using certain role-plays on particular topics (Taylor, 2018).

\section{SETTING THE STAGE}

In this chapter, we have discussed role-plays as a valuable teaching methodology in business education. Our review of the literature on active learning, the history and theoretical grounding of role-plays as an approach to business education, and the benefits and potential drawbacks 
of role-plays provides interested educators with considerable basis on which to justify their use of role-play simulations in the business classroom. In order to move forward and identify the specific ways to incorporate role-play simulations into their courses, educators must consider a variety of contextual factors that can influence the learning impact of role-plays. In Chapter 2, we turn to a discussion of such contexts, with specific ideas and recommendations for how educators can run role-plays in their own classes. 